\title{
WHAT EVERY GRAMMAR DOES: A REPLY TO PROF. ARBINI
}

\author{
STEPHEN P. STICH
}

Prof. Arbini's attention is flattering; his conclusions rather less so. The issues over which Arbini and I divide are many. Yet fundamentally, I think, our differences may be traced to disagreement about the nature and promise of the theories produced by contemporary generative grammarians. It is here that I shall focus my attention. Some of the points at which Arbini aims his criticism are quite crucial if we are to appreciate what sort of theory a grammar is. At other points his critique can best be viewed as the product of misunderstanding or polemical exuberance.

The first of the five sections that follow is aimed at setting to rest one such misunderstanding, provoked by my remark that a grammar commonly entails infinitely many statements of the form: $S$ is a grammatical sentence. On my critic's reading, this portends an heretical doctrine which would deprive grammars of the most basic empirical test against a native speaker's intuitions. The intended reading, by contrast, is the very soul of orthodoxy.

The section that follows attends to this basic empirical test in more detail. While Arbini and I agree that intuitions play a crucial role in the empirical confirmation of a grammar, he would have grammaticality be no more than accord with intuitions. On my view, grammaticality cannot be explained so simply. Recourse to the notion of a correct grammar is required. If I am right, then the paradox I proposed about the nature of linguistic intuitions survives Arbini's attempt to scuttle it. 
The concern in my third section is with what a grammar doesn't do. On my account, the rules of a grammar will not tell us how to recognize a grammatical sentence, nor how to produce the passive of a given active. Arbini sees a mystery here. But the mystery disolves if we attend carefully to what a grammar tells us and what it does not.

The fourth section resumes the topic of evidence for grammars. Though we agree that intuitions are important data for the grammarian, Arbini holds that the most striking aspect of the grammarian's data is the speakers' ability to produce the indefinitely many sentences of his language. The view is a common one and leads to much mischief. For besides painting a faulty picture of the confirmation of a grammar, it obscures the nature and interest of the grammarian's theory.

The final section is devoted to what speakers know. It is brief.

I.

To start off let us reflect on the notion of a grammar. What sort of thing is a grammar? A grammar is an empirical theory about a particular language. Like any empirical theory, a grammar may be right or wrong. One of the goals of a grammar is to provide a specification of the expressions which are grammatical sentences in the language. And one of the ways a grammar can be wrong is to classify as grammatical a sentence which is not. Commonly the grammarian will present his theory in the form of a system of generative rules paired with a collection of definitions. Among the definitions, some may be thought to be universal, applicable in the grammar of every natural language; others will be idiosyncratic to the particular language at hand. The rules and definitions together serve (among other things) to pick out a class of expressions, the "terminal language" of the grammar. These are the expressions the grammar "generates." And it is these the grammar claims to be grammatical. The claim, of course, is rarely explicitly stated. It goes without saying. But if a grammar can be wrong because it classifies as grammatical sentences which 
are not, then it must entail that some sentences are grammatical. Thus the claim that all and only the sentences generated by the grammar are fully grammatical is an intrinsic, if tacit, part of any grammatical theory. If we count the claim among the grammar's definitions, then "the definitions and rules entail a variety of statements ... of the form: $S$ is a grammatical sentence." 1 So much is commonplace. It pretends to be no more.

II.

A grammar is correct only if the sentences it holds to be grammatical actually are. With this there can be no quarrel. But what of the notion of grammaticality itself? What is it for a sentence to be grammatical? Arbini, it seems, endorses a view which he takes to be "traditional (since about 1955)." "According to [the traditional] view being grammatical is simply a matter of being an expression ... which accords with the intuitions of competent native speakers." $(P .76)$

"A grammar is a candidate for descriptive adequacy only if its output is grammatical in the sense of agreeing with the intuition of competent speakers of the relevant language."

$(P .72)$. In the usage I adopt, a speaker's intuitions are the pre-theoretic judgements he makes about expressions. There is no evidence that Arbini would demur here. Now if "accord" is to be rendered as a bi-conditional supplemented by the subjunctive mood, then a plausible reading of the traditional view is this: an expression is grammatical if and only if competent native speakers would judge it to be grammatical. But surely this will not do. For familiar generative grammars generate infinitely many sentences. Thus, for any natural number $n$, all but a finite fragment of the sentences a grammar classifies as grammatical contain more than $n$ words. But as $\mathrm{n}$ becomes substantial, speakers' intuitive judgements become quite useless. There is no saying how the average speaker would react to a sentence that takes a year to utter. Yet if we take the "traditional view" quite literally, it seems 
to require a grammar's pronouncements to accord with the speaker's even in such outlandish cases.

A more plausible account of grammaticality is to be found in some of Chomsky's earlier work. ${ }^{2}$ Rather than requiring that the grammar systematically capture the speaker's intuitions, it demands agreement between grammar and informant only in the case of relatively short sentences about which speakers have generally consistent intuitions. The grammarian's job is to find the simplest grammar that matches the speaker's intuitions in simple cases. ${ }^{3}$ In more complex cases the grammar itself is the arbiter of grammaticality. ${ }^{4}$ Agreeing with speakers' judgements in simple cases is only a necessary condition for a grammar's correctness. A correct grammar must also accord with other sorts of data and must mesh appropriately with a "linguistic theory" or general theory of grammar. A detailed account of these matters is a long story, one which I have tried to tell elsewhere. ${ }^{5}$ But the tale has a moral relevant to Prof. Arbini's dissent. Contrary to his "traditional" account, grammaticality cannot be defined directly by appeal to speakers' intuitions. Rather, it is the notion of correct grammar that is central. A correct grammar of a language is one which best handles the varied data available to the linguist and which meets the contraints imposed by a general theory of grammar. "To be grammatical is to be classified as grammatical by a correct grammar."6

If we allow that grammaticality is most plausibly explicated along the lines I have sketched, then we can, I think, revive the paradox Prof. Arbini would dismiss. It is granted that speakers' intuitive judgements about expressions are among the grammarian's principal data. But what, precisely, is the speaker supposed to be judging? If he is judging that a proffered expression is a grammatical sentence in his language, then, granting our analysis of grammaticality, he is judging that the sentence would be classified as grammatical by a correct grammar of his language. But surely this is not the belief an informant is expressing in reporting his linguistic intuitions. For a speaker is none the worse as an informant 
though he be quite innocent of the sophisticated notion of a correct grammar. What is more, such a judgement would appear to require the sort of justification that can be provided only by the careful construction of a grammar. So the informant, unless he moonlights as a grammarian, would be fobbing off judgements be cannot justify. If the informant is not judging that a proposed sentence would be generated by a correct grammar of his language, however, what is he doing when he offers his intuitions to the inquiring grammarian? This is the puzzle my account of linguistic intuitions aims at untangling.

III.

A grammar is an empirical theory. If it is correct then it will accord with speakers' intuitions, at least about most relatively short sentences. This is a modest claim about what a correct grammar will do. I doubt Arbini would disagree. There are, however, some things that, on my view, a correct grammar will not do. And here Arbini is less agreeable. Speakers of a language have a variety of skills which are foreign to non-speakers. With a bit of instruction a speaker of English, given a relatively brief declarative sentence, can provide its passive, or its negation, or can produce its associated yes-no question. An adequate grammar will specify which pairs of sentences are related as active and passive, as simple declarative and yes-no question, etc. It will not, however, tell us how to produce the passive of a given active, nor the negation of a given declarative. Arbini finds this a confusing doctrine.

An example will serve to clarify matters. Consider a grammar after the pattern of Syntactic Structures. (The argument works as well for grammars in the Aspects mold.) Suppose we are given such a grammar and one of its terminal sentences in the active voice. The problem posed: find the passive. To do it we must find the derivation of the sentence. We then repeat the derivation step by step, except this time we apply the optional passive transformation at the appro- 
priate point. The trick, of course, comes in the first step. For the task of finding a derivation of a given sentence is a non-trivial one and, more to our present point, it is not something the grammar tells us how to do. Given a grammar, there is a variety of explicit procedures that might be specified to facilitate the search for a derivation of an arbitrary string in the grammar's output. Among these search procedures, some will make explicit mention of the rules of the grammar. Conceivably others would not. But it is no part of a grammar to provide such a search procedure. And, as a bit of experimentation will reveal, constructing an efficient search procedure for a grammar of the modest complexity of Syntactic Structures is not a trivial-matter. Thus, although a grammar specifies which pairs of sentences are related as active and passive, it does not tell us how to produce the passive, given the active.

There is an obvious anaology with other formal systems. An axiomatization of the predicate calculus specifies which $w f f s$ are theorems. But it does not tell us how to produce a proof of a given theorem, nor does it tell us how to determine whether a given $w f f$ is a theorem. We can specify procedures for effecting the former task, but the specification is no part of the axiomatization of the predicate calculus.

Here we touch the issue of what speakers know, though only obliquely. If Fodor's views on tacit knowledge are accepted, then one of the explicit search procedures which specifies how to find the passive of a given active is to be counted as part of a speaker's fund of tacit knowledge. ${ }^{7}$ But, as we have seen, the rules which set out this procedure are not the rules of a grammar. So we may grant Fodor's doctine while yet denying that speakers know the rules of their grammar. My argument on this score maintained to show no more. $^{8}$

IV.

There is a further point about the nature of grammatical theory over which Arbini and I differ. The issue emerges only 
diffusely in his critique, and it requires some coaxing of his words to bring it into focus. But I think it worth the risk of misreading him to bring the dispute to the fore, since the view I would reject, if not Arbini's, is widely held nonetheless. And, by my lights, it poses a serious obstacle to a proper understanding of the sort of theory a grammar is.

"A speaker," Arbini writes, "knows how to produce the infinite number of sentences which comprise his native language. In fact, it is universally acknowledged among generative grammarians that it is this fact which provides a basic theoretical constraint upon the descriptive adequacy of alternative grammars of a given language." $(P .68)$ In view of this "basic constraint." Arbini is puzzled that my account of grammar focuses "only upon the ability to recognize such recondite theoretical properties as grammaticality, passivization, NP identification, etc." ( $P$. 68) For though he agrees "a speaker's competence also extends into these areas,"

$(P .68)$ he is troubled that in my portrait of the grammarian's doings "no attempt is being made to account for what the grammarian regards as the most striking aspect of his data, namely, the ability to produce (generate) the indefinitely many sentences of a given language." ( $P$. 70) At root, the dispute is over the role of the speaker's ability to produce the sentences of his language as data for the grammarian's theory. We agree that speakers are able to produce (at least) a vast number of the sentences of their native tongue. But on Arbini's view this fact is central to a grammarian's theorizing, while on mine it is largely irrelevant.

The issue needs some sharpening. How, specifically, is the speaker's ability to produce the indefinitely many sentences of his language supposed to serve the grammarian as data? Perhaps the most plausible reply would run like this: "The grammarian is interested in constructing a theory which (among other things) entails that a sentence is grammatical if and only if it is. Thus he must discover which sentences are in fact grammatical. It is here that the speaker's ability to produce sentences is to serve as data. If a speaker produces a 
given sentence, this is strong evidence that the sentence is grammatical." If our imagined respondant is judicious, he might add: "Of course, the fact that a speaker could produce a sentence is not conclusive evidence that it is grammatical. Speakers may, on occasion, let pass an ungrammatical pronouncement. But the grammarian should have weighty reasons before allowing his grammar to classify as ungrammatical an utterance a native speaker has evidenced his ability to produce."

The reply is reminiscent of the account of grammar once offered by Quine. ${ }^{9}$ Its defects are the same. A native speaker's ability to produce an utterance is no evidence for the utterance's grammaticality. While speakers can produce a vast number of grammatical sentences, they also can (and sometimes do) produce all manner of non-sentences ranging from almost grammatical slips of the tongue, lost thoughts, and utterances thought better of half way through, to blatant examples of meaningless noise. The fact that speakers can produce such utterances, or that they do, is quite irrelevant to the utterance's grammaticality. Grammar is not a matter of what speakers can produce. Rather is is the study of how they judge utterances. ${ }^{10}$ And it is for this reason that a speaker's intuitions, his presystematic judgements, and not the utterances he can or does produce, are the principal data invoked by the grammarian.

On my view, then, a grammar is quite literally a description of linguistic intuition. Grammar is a corner of psychology concerned to detail a speaker's ability to "recognize recondite properties." But the interest of this geography of linguistic intuition is not limited to those with a taste for the recondite. It is obvious that grammatical sentences are not the only ones speakers produce or understand; linguistic communication is not carried on wholly within the bounds of the grammatical. Yet it is equally obvious that there are substantial overlaps between the class of grammatical sequences and the class of sequences used in thought and communication. So there is reason to hope that an elaboration of the mechanisms which 
account for linguistic intuition will shed light on the processes of producing and understanding utterances. Still, a grammar is only a modest first step. Exploration of the psychological mechanisms that account for the intuitions a grammar describes is largely unbegun.

\section{V.}

Having staked out my position on grammar, it is time to attend to what speakers know. Here Arbini and I are closer than might appear at first. For he, it seems, is willing to admit what I took to be my most radical thesis. He grants that "a randomly selected informant clearly cannot be assumed to have long-standing beliefs about sentences which in all likelihood were unfamiliar to him until he was asked to pronounce upon their grammaticality." $(P .61)$ It follows that before the speaker has considered a sentence he does not believe it is grammatical. And if he doesn't believe it, he doesn't know it. Such as my thesis.

We are left with the problem of saying just what the grammarian is studying when he investigates a speaker's linguistic intuitions. Some students of language, albeit of questioned seriousness, have thought that the judgements about sentences and their parts offered by informants simply express part of the knowledge speakers acquire in learning their language. But this is incompatible with the thesis that Arbini and I share. My own solution is that informants are expressing newly acquired knowledge about perceived similarities and dissimilarities among expressions. The grammarian, then, is exploring the speaker's perceptual-cognitive capacity to acquire such knowledge on hearing or reflecting upon sentences.

My agreement with Arbini extends further, for I would allow that the question of whether speakers know the rules of their grammar is, as Arbini insists, an empirical question. It might be, for example, that the psychological mechanisms accounting for speakers' linguistic intuitions are parallel to (or 
even identical with) the mechanisms that underlie our propositional beliefs and knowledge. Should this prove to be the case, it would be a powerful argument that, despite the dissimilarities between the relation of speaker to grammar and the relation of believer to belief in more standard cases, still the former relation ought to be considered a species of belief (or knowledge). Such a discovery of parallel psychological mechanisms would be a paradigm of the extenuating circumstance which, on my account, would justify attributing knowledge of grammar to speakers. Other extenuating circumstances might be imagined. To date, however, all such extenuating circumstances must be imagined. None, as best I can tell, has been discovered. We know neither the mechanism underlying intuition, nor the mechanism underlying belief, nor have we any reason to think them identical.

Paradoxically, Arbini and others who would attribute knowledge of the rules of a grammar to speakers do not always treat the attribution as an empirical conclusion. Thus, Arabini writes: "The relevant account of knowledge occurs in the attempt to explain how the appropriate properties come to be attributed to the data in question in terms of what the speaker must be presumed to know if he is to process this data." (P. 63; emphasis added) The "data" in question are newly confronted sentences; the properties are grammaticality, being related as active and passive, etc. So for Arbini, the speaker "must be presumed to know" his grammar if we are to explain how he attributes various grammatical properties to sentences. But why must he be presumed to know anything? It is granted that the speaker makes such attributions and that there is some mechanism or other which explains how he comes to make them. But we do not know what this mechanism is. To stipulate that the explanation of intuitions must be in terms of a speaker's knowledge of grammar (or of anything else) is to settle an empirical question by fiat.

It is for similar reasons that I would challenge Chomsky's characterization of grammar as the study of competence, where competence is "the speaker-hearer's knowledge of his 
language." On presentely available evidence there is little reason to think the relation between a speaker and his grammar is knowledge. The disanalogies between this relation and more standard cases of knowledge are patent. To be sure, less obvious analogies may be discovered. But Chomsky's characterization of grammar as the study of competence would seem to settle by definition what is in fact an empirical question.

THE UNIVERSITY OF MICHIGAN ANN ARBOR, MICHIGAN 48104

USA

RECEIVED: 24 APRIL 1972

\section{NOTES}

1 Quoted by Ronald Arbini, "On Explanations of Linguistic Competence," in the present issue of this Journal, from S.P. Stich, "What Every Speaker Knows," Philosophical Review, LXXX, 4 (1971). Hereafter the latter paper will be cited as WESK; references otherwise unidentified will be to Professor Arbini's paper.

2 Cf., for example, Syntactic Structures, The Hague: Mouton (1957), pp. 13 ff.

3 Even here the grammarian can take cautious liberties, overruling the judgement of an informant now and again if so doing will substantially simplify the grammar. Practiced with discretion, such a move is an instance of the common scientific practice of discarding a bit of data as tainted by factors as yet unknown.

4 In more recent writings (e.g. Aspects of the Theory of Syntax, Cambridge, Mass., MIT Press (1965), Ch. I) Chomsky offers a variant account of grammaticality. On this version, as expression is grammatical if and only if it accords with the intuitions of an "idealized speaker-hearer." The two accounts amount to much the same thing, however, since we assess the intuitions of an idealized speaker-hearer by constructing the simplest grammar that accords with the intuitions of our less than ideal subjects on relatively short and simple sentences.

5 Cf. my "Grammar, Psychology and Indeterminacy," The Journal of Philosophy, $69,22(1972)$.

6 WESK, p. 478 . Cited by Arbini, p. 75.

7 For Fodor's view, cf, J.A. Fodor, "The Appeal to Tacit Knowledge in Psychological Explanation," The Journal of Philosophy, 65 (1968), pp. 627-640.

8 It is understandable Arbini should charge "that, if Fodor is correct, Stich's thesis is false, and, further, we are given no reason to suppose that Fodor is wrong." $(P$. 67). For he reads my thesis as the bold one that speakers, qua speakers, know nothing. My retreat from this ambitious doctrine is tucked away in a footnote (WESK, fn. 6, p. 481). The concern of my study was grammar, and my throwis was threefold: speakers know neither the rules of their grammar, nor the principles of linguistic theory, nor what their grammar entails about individual sentences. 


\section{STEPHEN P. STICH}

9 W.V. Quine, "The Problem of Meaning in Linguistics," in From a Logical Point of View, second edition, revised. New York and Evanston: Harper Torchbooks 10 (1963).

This is a bit oversimplified. For a more careful statement of the view ef. my "Grammar, Psychology and Indeterminacy," op. cit. 